\title{
Adverse Effects of Chromium, Cadmium and Zinc on the Growth and Metabolic Activities of Pulse Crops and their Key Management Strategies: A Review
}

\author{
Srabani Kar and Ravindra Prasad* \\ Department of Genetics and Plant Breeding, Institute of Agricultural Sciences, Banaras \\ Hindu University, Varanasi-221 005, (India) \\ *Corresponding author
}

\section{A B S T R A C T}

\section{Keywords}

Oxidative stress,

Sustainable agriculture,

Micronutrient, Phytoremediation, Heavy metals, Pulse crops

\section{Article Info}

Accepted:

04 March 2020

Available Online:

10 April 2020
Pulse crops are an integral part of Indian agricultural economy next to the cereals and oilseeds in terms of production, productivity and economic value. These crops are richest source of protein and energy but in India such crops are largely cultivated under energy starved and polluted conditions, resulting affecting the metabolic activity and limiting the yield. Agricultural soil contaminated by heavy metals becomes a severe environmental issue in this day due to its potential adverse ecological effects. Crop plants faced oxidative stress upon exposure to heavy metals and metalloids which leads to cellular damage. Chromium, Cadmium and Zinc are widely used in industrial purpose and considered as very dangerous environmental pollutants that contaminates soil and water. In the nature, Chromium exists in two valence forms viz., $\mathrm{Cr} 3+$ and $\mathrm{Cr} 6+$, chromite mineral which is mainly composed of $\mathrm{Cr} 6+$ is more toxic and mobile than $\mathrm{Cr} 3+$. Cadmium belongs to the first class of dangerous goods in terms of environmental risk, toxicity, mobility and the ability to accumulate in food chain. Zinc is an essential micronutrient required for optimum growth of crop plants but it plays toxic role to plants when present in soil at elevated concentration. Polluted soil has posed a serious issue to sustainable agriculture and human health worldwide; its affects the plant growth and enzymatic activities as well. Metabolic hindrances by chromium have also been described in crops by direct effect of enzymes and by producing ROS may cause oxidative stress. Phytoremediation has received a great deal of attention in recent years which include phytoextraction, phytostabilization, rhizofiltration and phytovolatilization considered a promising, energy and cost effective way to rehabilitate metal-contaminated environments. In addition, the use of tolerance genotypes against metals toxic soil is one of the key eco-friendly approaches to enhance the yield of pulse crops. 


\section{Introduction}

As compare to cereals, pulse crops are more important in context to its nutritive values which belongs to family Leguminaceae (Singh et al., 2011). Major pulse crops which are cultivated in India are chickpea (Cicer arietinum L.), Pigeon pea (Cajanus cajan L.), Black gram (Vigna mungo L.), Green gram (Vigna radiate L.), Lentil (Lens culinaris L.), Field pea (Pisum sativum L.), Rajmash (Phaseolous vulgaris L.), Soybean (Glycine max L.) etc. India is the largest producer and consumer of pulses in world and contributes around 25-28 per cent to the global pulse production (Singh et al., 2011). In the year 2018-19 total pulse production estimated by India's Ministry of Agriculture is around 24.03 million metric tons. Pulses are an integral part of vegetarian diet of a large population in India. Besides being a rich source of proteins and essential amino acids; such crops also maintain soil fertility through biological nitrogen fixation in symbiotic association with Rhizobium bacteria present in their root nodules (Pooniya et al., 2015). However; its production is hampered by soil pollution due to industrialization as well as cropping intensification. Industrializations cause release of several pollutants among these; heavy metals are one of the most dangerous pollutants which become serious issue for the past few decades. An increase of their contents in soil that results in the absorption as well as the accumulation of these toxicants by plants which is very harmful to plant growth and health of human and animals. Metals and metalloids including $\mathrm{Pb}, \mathrm{Cu}, \mathrm{Zn}, \mathrm{Cd}, \mathrm{Ni}, \mathrm{Cr}, \mathrm{As}, \mathrm{Se}$ etc. are toxic to organisms at high concentration, they are persistent pollutants in soil because they are non-degradable (Pajuelo et al., 2011). Heavy metal pollution affects soil structure, soil fertility, population diversity, vegetation, microbes and is a major threat to livestock as well as human via the food chain. Plants that are able to hyper accumulate metals are an optimum option for phytoextraction because they can accumulate large amounts of metals or metalloids or trace metals in shoots (at least $0.01 \%$ dry weight for $\mathrm{As}, \mathrm{Cd}$ and some trace metals viz., $0.1 \%$ dry weight for $\mathrm{Cu}, \mathrm{Pb}$, $\mathrm{Co}$, and $\mathrm{Cr} ; 1 \%$ dry weight for $\mathrm{Ni}, \mathrm{Zn}$ and $\mathrm{Mn})$ without any visible symptoms such as wilting or necrosis of leaves, root discoloration and plant growth (Prasad and Freitas, 2003). Cadmium is the most severe heavy metal, since it is characterized by high mobility and a toxic effect on living organisms. The hexavalent chromium compounds mainly chromates and dichromates are extensively used in diverse fields of industry leading to environmental pollution. It is a highly toxic non-essential metal for microorganisms and plants, due to its widespread industrial use, chromium $(\mathrm{Cr})$ has become a serious pollutant in diverse environmental settings (Crevantes et al., 2001). Plants, including legumes/oils are able to uptake heavy metals like chromium from soils that result in many adverse effects like inhibition of seed germination, seedling development which eventually lowering the crop yield. Gill et al., (2016) reported that chromium toxicity is linked with upregulated stress responsive metabolic pathways like the tryptophan, vitamin B6, sulphur and nitrogen in Bressica napus and therefore, such information could be taken as a bench mark for the researchers who are working in the field of related stress physiology and molecular biology for exploring the fact occured during stressed condition and then developing the tolerance genotypes of the crop plant for human being. Uptake of chromium by the plant depends on its available form and concentration in soil or water around, as well as plant species and their physiological state. However, the mechanisms of uptake and distribution of chromium in vegetative and reproductive plant organs have not been sufficiently 
studied. Chromium is not known as an essential element for plants and therefore, has no specific mechanisms for assimilation by plants. Both active and passive transport systems were suggested to participate in uptake of this element in plants. Active transport is proposed to be responsible for absorption of chromium ions at low concentrations, whereas chromium intake is induced by passive facilitated diffusion at its high concentrations. It is well established that Cr6+ is absorbed by roots mainly via an energy-dependent transport, while $\mathrm{Cr} 3+$ penetrates the plant. Effects of heavy metals are connected with inhibition of certain metabolic processes, including biosynthesis of chlorophylls and proteins as a result progressive chlorosis, necrosis, and decreased protein content are typical indication of heavy metal toxicity to plants. Since, above discussed issue is the very challenging issue faced by the researchers or farmers in modern agriculture hence, the basic aim of this review paper is to understand the mechanism of crop plants under metal toxicity condition and figuring out this issue through various approaches and producing the tolerance genotypes of crop plants to enhance the yield of crops for food security/meet the demand of growing population.

Toxic effects of heavy metals on the growth and enzymatic activity of the crop plants

The term heavy metal generally includes only the elements with specific gravity more than five but this term used by scientist for a vast range of metals and metalloids that are poisonous to plants like cadmium, copper, cobalt, iron, nickel, manganese, zinc, arsenic etc. Few transition metals and heavy metals like sodium, calcium, potassium, iron, zinc, cobalt etc. are essential micronutrients at certain level (Hossain et al., 2012). The toxicity of heavy metals is manifested in many ways when plant cells accumulate them at high levels. Heavy metals can be divided into two groups: redox active viz., $\mathrm{Fe}, \mathrm{Cu}, \mathrm{Cr}$, $\mathrm{Co}$ ) and redox inactive such as $\mathrm{Cd}, \mathrm{Zn}, \mathrm{Ni}, \mathrm{Al}$, etc. (Hossain et al., 2012). Legumes can uptake heavy metals like chromium from soils that cause progressive chlorosis, necrosis and decreased protein content are typical signs of heavy metal toxicity to plants. Transfer of toxic elements to the animal as well as human food chain is a threat to be faced in future. The enhanced production of Reactive Oxygen Species (ROS) is considered to be one of the most important features of $\mathrm{Cr} 6+$ toxicity. ROS, such as superoxide anion radical (O2--), hydrogen peroxide $\left(\mathrm{H}_{2} \mathrm{O}_{2}\right)$, and hydroxyl radical $(\mathrm{OH} \cdot)$, are highly active molecules, they can cause oxidative modification of proteins, lipids, and nucleic acids. In response to heavy metal exposure, plants unregulated various enzymatic or non enzymatic mechanisms that help to support redox balance and prevent oxidative damage under heavy metals stressed conditions.

\section{Chromium and its toxic effect on growth of crop plants}

Accumulation of chromium disturbs metabolic processes in plants which eventually affects morphological and physiological growth. Seed germination is primary physiological process, which is influenced by toxic metals. The treatment with $200 \mu \mathrm{M}$ Cr6+ was shown to reduce by 25 per cent germination of Echinochloa colona seeds and has reported that populations of Echinochloa colona occurring naturally on chromite mine spoils appear to have developed metal tolerance ability as well (Rout et al., 2000). The presence of $\mathrm{Cr} 6+$ at elevated concentrations in the soil reduces 48 per cent seed germination of Phaseolus vulgaris, the high levels $(500 \mu \mathrm{g} / \mathrm{g})$ of hexavalent chromium in soil (as Orocol TL) affect germination and growth, of crops while a high level of organic matter significantly 
reduced chromium toxicity on germination (Parr and Taylor, 1982). Decreased seed germination with increasing concentration of chromium ions was also observed for cowpea crops. The death of seed and obstructed seed germination may be described by activation of proteases or retardation of amylase activity by chromium with the subsequent decreases. Other toxic effects of chromium are the prevention of root growth was widely observed. Inhibitory effects of chromium on the root elongation were found in wheat and vigna crops. The toxic effects of heavy metals on roots includes, reduction of length, biomass, diameter, destruction of root hairs or decrease in root numbers, increase or decrease of lateral roots formation etc. It has been noted that chromium also affects growth of leaves, the main photosynthetic pillar of plant. Increasing chromium concentration leads to a significant reduction in the leaf area and leaf biomass, which is accompanied by decreased photosynthesis and promotion of chlorosis and necrosis of leaves. In plant mitochondria Cr6+ can arrest electron transport by substituting copper and iron ions in prosthetic groups of many carrier proteins. In fact, Cr6+ at concentrations of 20 and $200 \mu \mathrm{M}$ inhibited cytochrome oxidase in mitochondrial respiratory chain in pea plants (Dixit et al., 2002). Chromium can be beneficial and toxic to animals and humans depending on its oxidation state and concentration (Shankar et al., 2009). At low concentration, trivalent chromium is essential for animal health (Katz and Salem, 1994), whereas hexavalent chromium is a potent, extremely toxic to living organism. In other hand chromium interacts with plant at cellular level mainly by producing reactive oxygen species like super oxide radicals, hydroxyl radicals (Shankar and Pathmanabhan, 2004) which hamper the growth and development of crop plants. The toxic effects of Chromium (VI), how can interfere physiological, biochemical and molecular activities/mechanism of crop plants can be understand by Figure 1 (Mohammad et al., 2011) and Figure 2. Uliana et al., (2018) also studied the effect of chromium exposure alone and in combination with nodule rhizobacteria on selected growth parameters and ROS homeostasis in Pisum sativum plants (Figure 3) and suggested that oxidative stress of chromium (VI) has negative impact on crop plant in both without nodule rhizobacteria and with nodule rhizobacteria however, in addition of nodule bacteria on some extent could limits the toxic effect of chromium (VI) on the growth and development of crop plants. Several studies indicate that plants have ability to reduce the chromium toxicity (VI), in this context Lytle et al., (1998) carried an experiment and reported that Eichhornia crassipes (water hyacinth) that is a wetland plant and planted into constructed wetland treatment system containing heavy metal-contaminated wastewater and has an excellent potential for phytoremediation of chromium in wastewater because, it has ability to absorb and remove toxic $\mathrm{Cr}(\mathrm{VI})$ and then reduce it to nontoxic $\mathrm{Cr}(\mathrm{III})$. Hence, the $\mathrm{Cr}(\mathrm{VI})$ detoxification process of Eichhornia crassipes and other wetland plants has the potential to be recommended to utilized for the in situ remediation of $\mathrm{Cr}(\mathrm{VI})$ contaminated groundwater.

The largest source of cadmium release to the environment is the burning of fossil fuels and the incineration of municipal waste materials. Cadmium is also used in pigments, batteries and plastics; it may also escape into the air as a by-product from the smelting of zinc, lead, or coppers. The importance of micro-nutrient in limiting crop production in several countries of the world is well recognized (Neumann et al., 1998). Removal of excess micro-nutrients as a consequence of adoption of high yielding varieties and intensive cropping together with a shift towards high analysis of NPK fertilizers has caused decline 
in the level of micro-nutrients in soil that required for normal productivity of crops. It is noticed that at higher concentration zinc leads to physiological and morphological disturbances and eventually to decreased crop yield. Higher concentration of $\mathrm{Zn}$ in the plant tissue seriously affects activity of several enzymes and other fundamental metabolic processes. It is also reported that an excess of $\mathrm{Zn}$ also reduced photosynthetic rate as a part of enzymes concerned in the photosynthesis. Nitrogen metabolism is also affected in diverse ways by an excess of Zinc. The protein content is found to be reduced; nitrogen-fixation and nitrate reductase activity was also concealed by Zn toxicity. Naz et al., (2015) carried out an experiment with aim to assess effects of different heavy metals like $\mathrm{Zn}, \mathrm{Ni}, \mathrm{Pb}, \mathrm{Cd}$ and $\mathrm{Cr}$ on chickpea and concludes that among all the heavy metals tested, $\mathrm{Cr}$ proved to be the less toxic to the plants resulting highest root and shoot production, the heavy metal concentration effected in the order of $\mathrm{Cd}>\mathrm{Ni}>\mathrm{Zn}>\mathrm{Pb}>\mathrm{Cr}$ on chickpea plants.

\section{Cadmium and its toxic effect of crop plants}

Presence of contamination in soil with high concentrations led to its accumulation in plants in quantities exceeding threshold limit value. The phytotoxic effect of cadmium is expressed in plant height reduction and in the number of leaves at all levels of contamination with the higher dose. The main reason for the decrease of the content of green pigments in the presence of heavy metals in the suppression of the biosynthesis of chlorophyll that is mainly due to the direct action of metals on the activity of biosynthetic enzymes in particular, protochlorophyll oxydoreductase and chlorophyll synthase. The hindrances of chlorophyll biosynthesis in the presence of cadmium can be caused by its displacement of $\mathrm{Mg} 2+$ ion in the chlorophyll molecule (Hasan et al., 2009).

\section{Effect of cadmium on the plant growth, nodulation and dry mass}

Cadmium is not come under category of essential nutrient and inhibits plant growth if present in soil with very high concentration. However, it has also been reported that even at relatively low concentrations it changes plant metabolism (Van Assche and Clijsters, 1990). The presence of cadmium in the soil decreases the growth of soybean (Dowdy and Ham, 1977; Cataldo et al., 1983) and chickpea (Hasan et al., 2007b). High concentrations of $\mathrm{Cd}$ decreased cell growth as well as whole plant growth. The interaction of Rhizobium in the nodules of chickpea was found to be very sensitive to heavy metals resulting in a decrease in dry mass of chickpea and green gram (Athar and Ahmad, 2002). An increase in $\mathrm{Cd}$ concentration decreased the fresh mass in mungbean (Shen et al., 1990). Moreover, a marked decrease in root and shoot mass of Vigna ambacensis was observed when treated with low concentration of Cadmium. The presence of heavy metals in the soil decreased the yield of symbiotic nitrogen-fixing organisms and the number of nodules per plant (Vigue et al., 1981). The presence of $\mathrm{Cd}$ decreased nodulation and nitrogenase activity in Phaseolus vulgaris (Dowdy and Ham, 1977; Vigue et al., 1981), Trifolium repens (Granth et al., 1988), and in Pisum sativum (Dhingra and Priefer, 2006). The Nitrogen assimilation in pea plant is severely affects on exposure to $\mathrm{Cd}$ as reported by (Hernandez et al., 1995; Dhingra and Priefer, 2006). The positive correlation was observed between leghemoglobin content and nitrogenase activity (Darkaro, 1995; Comba et al., 1998) and both these parameters exhibited a parallel decrease in the presence of Cd (Fernandez et al., 1996). The oxidation stress generated by $\mathrm{Cd} 2+$ accelerated senescence of nodules in soybean plants. The effects of cadmium exposure alone and in combination with nodule rhizobacteria on 
selected growth parameters and ROS homeostasis in Pisum sativum plants presented in figure 4 (Chubukova et al., 2015), it show that under inoculation with nitrogen fixing bacteria, the nitrogenase activity, plant length and dry mass, numbers of nodule and contents of leghemoglobin were increased whereas it was decreases in without treated plant with bacterial culture. Such finding reveals that under heavy metals polluted agricultural land farmers should follow practices to minimize the toxic effect of heavy metals and increase the productivity of crop plants.

\section{Effect of cadmium on nitrate reductase activity}

Nitrate reductase (NR) is the primary enzyme in the nitrate assimilation pathway which is the limiting factor in plant growth and development and its level is influenced by a variety of environmental factors (Andrews, 1986). The presence of $\mathrm{Cd}$ in the soil inhibited the assimilation of $\mathrm{NO}_{3}$ and the activity of nitrate reductase in the crop plants loke Maize, Pea (Burzynski, 1988), Bean and Chick pea (Ali et al., 2007; Hasan et al., 2007a). The presence of lowest concentration of cadmium in the soil is not so hamper the crop growth and development however; its higher concentration leads to the toxic effect on crop plants and significantly lowers the yield of crop plants (Burzynski, 1988).

\section{Zinc (Zn) toxicity and its effect of the plant growth}

A toxic concentration of $\mathrm{Zn}$ in plant tissue seriously affects the activity of several enzymes and other basic metabolic processes. Several study declared that a surplus amount of $\mathrm{Zn}$ also reduced photosynthesis process which is key part of enzymes involved in the photosynthesis. Excess amount of $\mathrm{Zn}$ is also disturbing the nitrogen metabolic in various ways which leads to limits the output of crop plants. Zn toxicity also camouflaged nitrogenfixation and nitrate reductase activity (Phalcon, 1989). Excess of $\mathrm{Zn}$ in plants interfere the uptake, transport, osmotic and regulation of essential ions as a result disruption of metabolic processes such as transpiration, photosynthesis and enzyme activities (Broadley et al., 2007; Abbas et al., 2009).

Zinc toxicity in plants also enhances oxidative stress by producing free radicals and reactive oxygen species (Weckx and Clijsters, 1997). These ROS are highly reactive and cause death of the plants by degrading membrane lipids, proteins, pigments and nucleic acids. To adapt with the damages caused by the ROS, plant cells possess their own endogenous antioxidant defense system made up of both enzymatic as well as nonenzymatic components like peroxidase (POD) and catalase (CAT) which represent the endogenous defense of plant cells. These enzymes are present in different forms in several cell compartments and their expression is genetically controlled and managed by developmental stimuli, according to the necessity to remove ROS produced in cells (Mittler et al., 2004). It is also well claimed that flavonoids and polyphenols are natural antioxidants. The effect of $\mathrm{Zn}$ exposure alone and in combination with nodule Rhizobacteria on selected growth parameters and ROS homeostasis in Lens culinaris plants presented in Figure 5. It's revealed that when plant exposed with $\mathrm{Zn}$, its shows decreasing the nitrate and CAT activity, leghemoglobin contents, nodule numbers and dry mass, plant length and dry mass and eventually seed yield whereas such parameters were increases when plant was exposed with cadmium and treated with $R L-9$ of nitrogen fixing Rhizobium bacterium (Ibrahim and Shabbir, 2014). The combined application of micronutrients like Zinc and 
Boron showed significant positive impact on lentil yield than the single application of either Zinc or Boron reported by Quddus et al., (2014).

The effects of zinc exposure alone and in combination with selective strain of Rhizobacteria on selected growth parameters and ROS homeostasis in Lens culinaris plants given in Figure 5 (Ibrahim and Shabbir, 2014). Through this figure it's noticed that under without use of bacterial treatments the parameters like nitrate, urease activity, CAT activity, numbers of nodule, plant dry mass, plant growth and yield of the plant could decreases however, these parameters are increases when plant is treated with RL9 strain of nitrogen fixing bacteria. Thus, unique strain of nitrogen fixing bacteria has ability to play the paramount role to reduce the toxic effect of heavy metals present in cultivated land and help to plant for its proper growth and development.

\section{Chelation of cadmium ion}

In order to adapt with highly toxic metals or to maintain the level of essential metals within the physiological range, plants have evolved a variety of complex mechanisms for metals tolerance. Among these, accumulation and detoxification is a mechanism that serves to control the uptake and accumulation of heavy metals. Different plant species, commercial varieties, cultivars and ecotypes have the wide range of tolerance ability to excess concentrations of heavy metals. Other mechanism for heavy metal detoxification in crop plants is chelation by a ligand and in some cases; the subsequent compartmentalization of the ligand metal complex is operated. Formation of these complexes is termed as chelation and the complexes are known as chelates.

The legume-rhizobia symbiosis has been promoted as a novel and effective method to employ plant-microbe interactions for phytoremediation, especially phytostabilization and resistance rhizobia used for phytoremediation could act on metals directly by chelation, precipitation, transformation, biosorption and accumulation (Hao et al., 2014). Most of the reported legume-rhizobia symbioses are being used for phytostabilization, considered safer for consumption (Dary et al., 2010).

\section{Zinc toxicity and its defense mechanism}

Flavonoids can directly react with superoxide anions and lipid peroxyl radical and consequently inhibit or break the chain of lipid peroxidation. This radical scavenging activity of extracts could be related to the antioxidant nature of polyphenols or flavonoids, thus contributing to their electron/hydrogen donating ability. Plant phenolic compounds also participated in the defence system of plant against oxidative stress. The antioxidant action of phenolic compounds is due to their high tendency to chelate metals. Phenolics possess hydroxyl and carboxyl groups have ability to bind particularly $\mathrm{Fe}+2$ and $\mathrm{Cu}+2$ (Jung et al., 2003). The roots of many plants exposed to heavy metals exude high levels of phenolics. They may inactivate iron ions by chelating and additionally suppressing the superoxide driven reaction, which is believed to be the most important source of ROS (Arora et al., 1998). This chelating ability of phenolic compounds is probably related to the high nucleophilic character of the aromatic rings rather than to specific chelating groups within the molecule (Morgan et al., 1997). An enhancement of phenylopropanoid metabolism and the amount of phenolic compounds can be observed under different environmental factors and stress conditions (Sakihama and Masaki, 2002). Similarly, an increase in soluble phenolics, such as intermediates in lignin biosynthesis can reflect the typical anatomical change induced 
by stressors: increase in cell wall endurance and the creation of physical barriers preventing response against harmful action of heavy metals. Zinc come under micronutrient and plays an important role for crop plants however, excess does cause toxic effect on crop growth. The foliar spray zinc showed balanced use and better performance with protein contents, total soluble sugar, nitrate reductase activity and chlorophyll contents as compared to the soil application (Shalini and Vijai (2018). Thus, farmers should adopt the foliar application of zinc to take the more benefit and avoid the soil application which may leads to pollute the agricultural soil because of its imbalance/excess application.

\section{Key management strategies}

Several studies have suggested that nitrogenfixing bacteria can decrease the heavy metal toxicity on host plants. The preventive measures are proposed to be associated with the accumulation of the metals in the nodules. The nodule bacteria are exposed more to heavy metals rather than the host plant. Resistance of the bacteria to heavy metals is species as well as strain-specific. It can be justified that if bacteria have powerful defense mechanisms against heavy metal toxicity, the protective effect of these bacteria on the host plant will be more prominent. Some biochemical responses of heavy metal stress in plants are characterized by the synthesis of GSH (Glutathione), amino acids like proline and singling molecules like Salicylic Acid (SA). SA is a natural signal molecule which plays a major role in controlling a number of physiological and biochemical processes making plants resistance to biotic and abiotic stresses (Freeman et al., 2004). Accumulation of proline in response to heavy metals stress has also been widely reported (Siripornadulsil et al., 2002), demonstrated that increased proline levels, enhanced the protection against
$\mathrm{Cd}$ in micro algae. Moreover, many heavy metal tolerant plants have also been reported to possess substantially elevated constitutive proline levels in the absence of excess heavy metal ions when compared with their nontolerant relatives. Importantly, proline reduces $\mathrm{Cd}$ stress not by sequestering of $\mathrm{Cd}$ but by reducing Cd-induced free radical damage and maintaining a stringent reducing environment (higher GSH levels) within the cell. In seeking additional supporting evidence for this, it is discussed that in Mung bean exogenous proline induces heavy metal $(\mathrm{Cd})$ tolerance by maintaining a higher GSH level and GSH metabolizing enzymes. Rhizobium galegae was more resistant to $\mathrm{Cd} 2+$ than Rhizobium leguminosarum. Most likely, the microsymbionts of Galega orientalis have a strong system for inactivation of toxic components in the soil, which makes them less sensitive to various xenobiotics. It is found the strains of rhizobium bacteria that are most resistance to the toxic effect of cadmium, these are Galega orientalis and Pisum sativum microsymbionts (Chubukova et al., 2015). Like other bacteria, protective mechanisms of rhizobia against chromium toxicity apparently include direct and indirect reduction of $\mathrm{Cr} 6+$ to $\mathrm{Cr} 3+$, metal binding with further isolation or elimination, and up regulation of antioxidant defense. But $\mathrm{Cr}$ influence, now only it is found that inoculation with highly effective nitrogenfixing bacteria declined the toxic effects of chromium (IV) on Pisum sativum. The protective effects included enhancement of the length of shoots and mass of the plant roots and increased levels of photosynthetic pigments like chlorophylls, carotenoids and anthocyanins as compared with the effects of chromium on pea plants without inoculation. In addition, it is also noticed that treatment with potassium dichromate did not affect level of oxidized proteins but increased levels of lipid peroxidation products and decreased catalase activity in plants preinoculated with 
nitrogen-fixing rhizobia, but not in non inoculated pea plants. Despite increased levels of lipid peroxidation products, pea plants grew better when treated with $\mathrm{Cr}$ in the presence of nodule (Uliana et al., 2017).

Fig.1 Toxic effects of Chromium (VI) on the plant growth and enzymatic activity

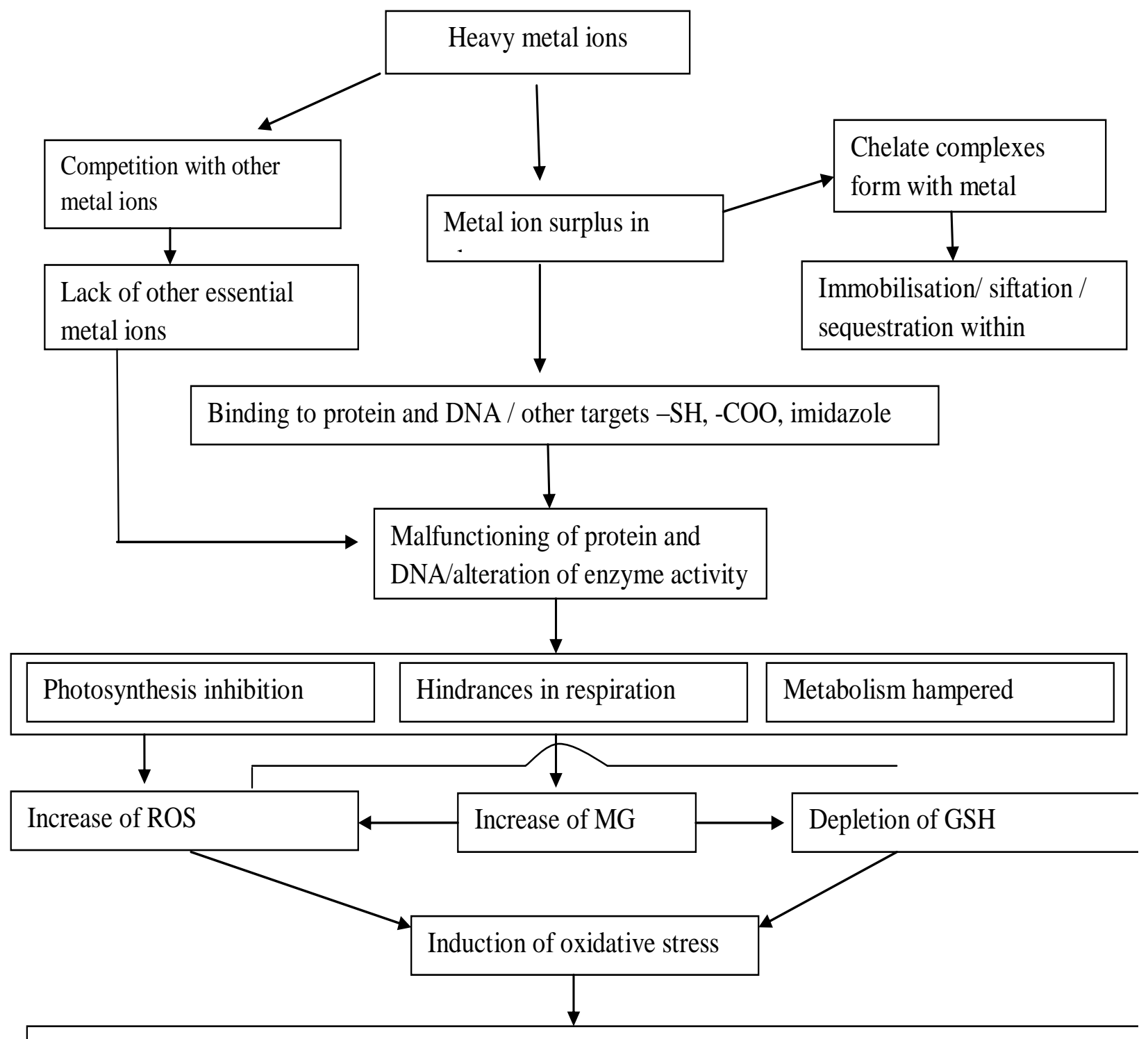

Alteration of cell membrane, DNA damage, gene mutation, protein oxidation, lipid peroxidation and cell

Growth inhibition and damage 
Fig.2 Biochemical and molecular mechanisms of heavy metal mediated ROS induction and its negative impact on the growth and development of crop plants

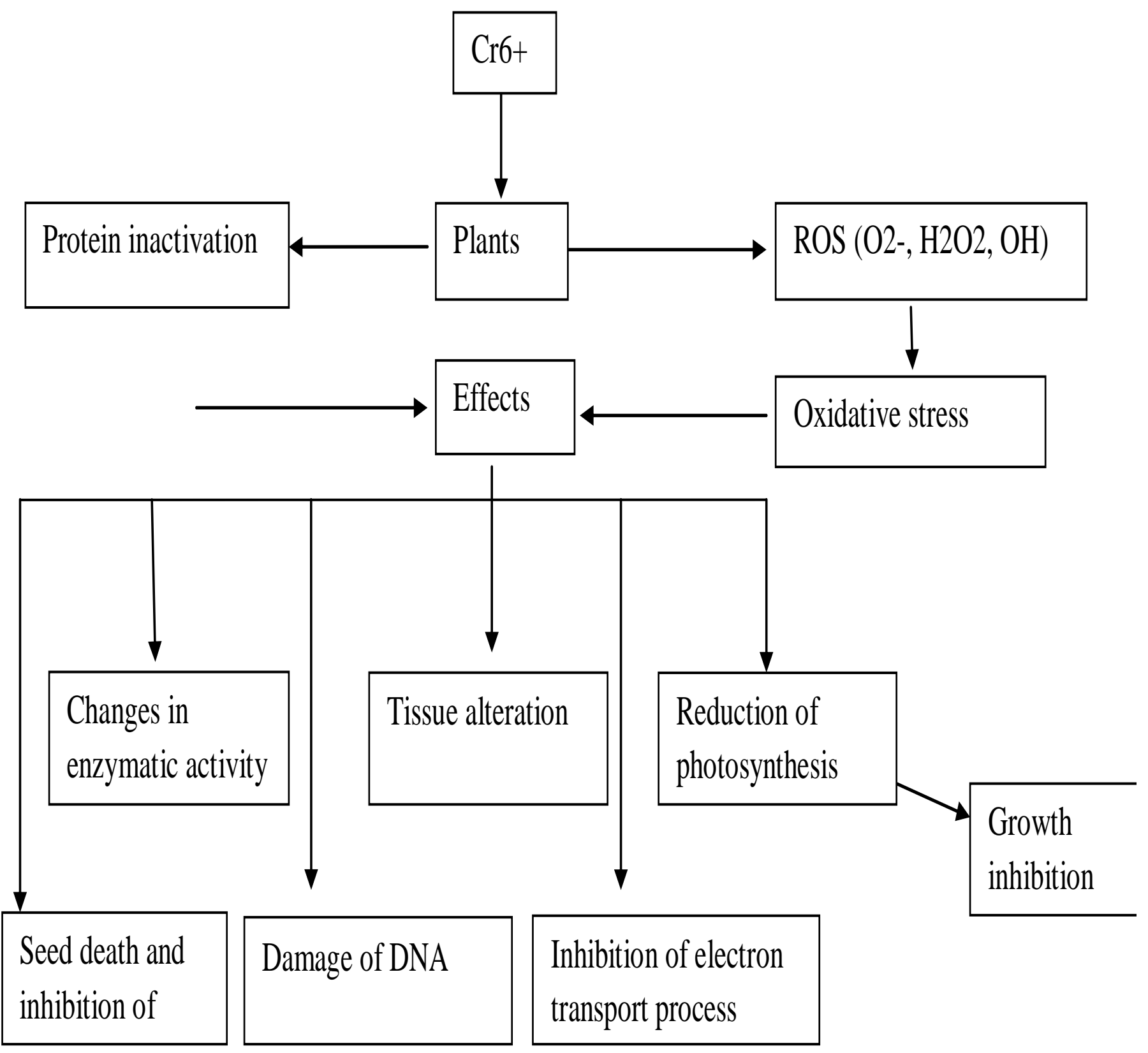


Fig.3 Effects of Chromium exposure alone and in combination with nodule rhizobacteria on selected growth parameters and ROS homeostasis in Pisum sativum plants. Arrows $\boldsymbol{\uparrow}^{\text {and }} \downarrow$ indicates the increase and decrease in the parameters respectively.

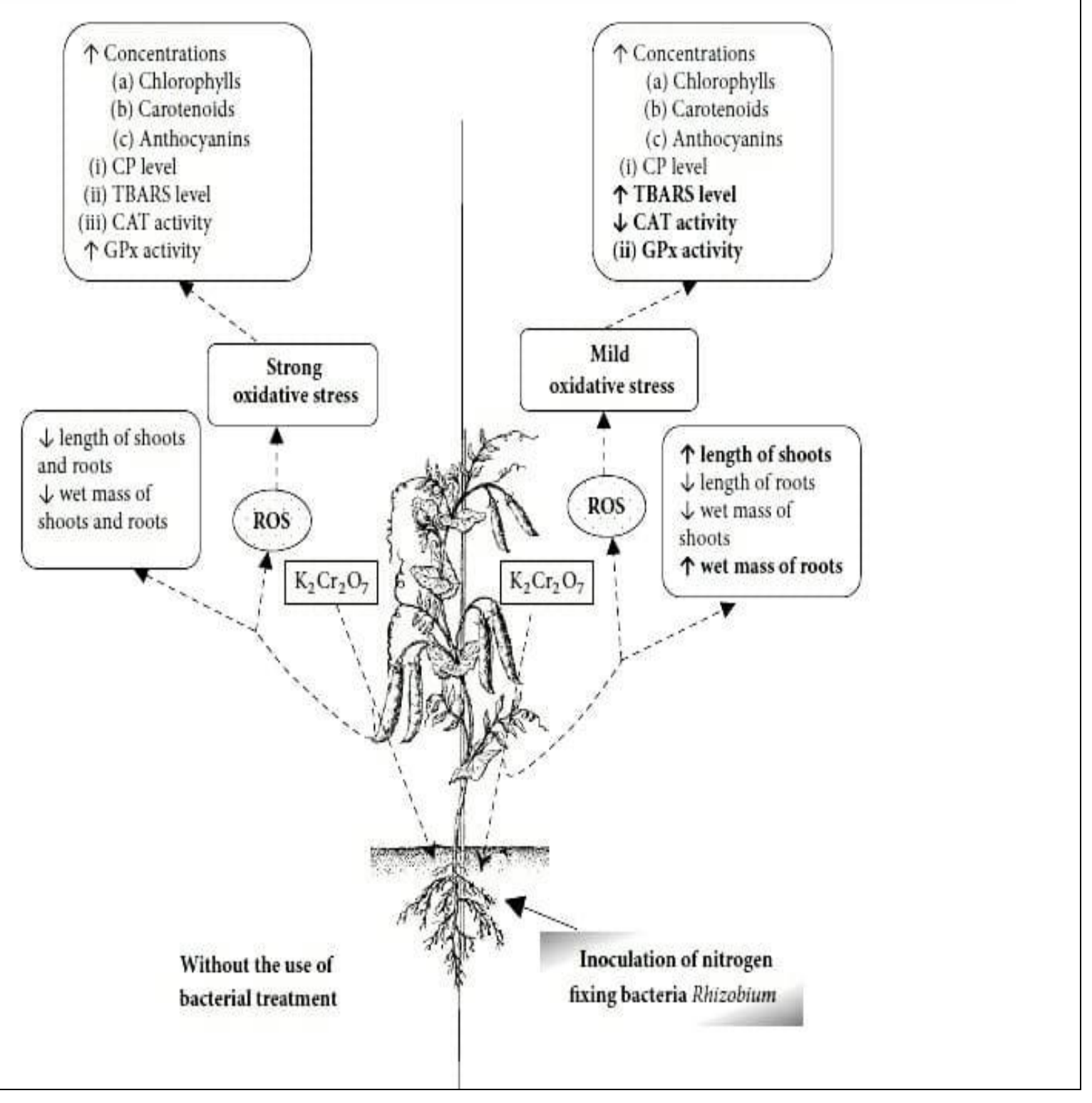


Fig.4 Effects of Cadmium exposure alone and in combination with nodule rhizobacteria on selected growth parameters and ROS homeostasis in Pisum sativum plants. Arrows and $\downarrow$ indicates the increase and decrease in the parameters respectively.

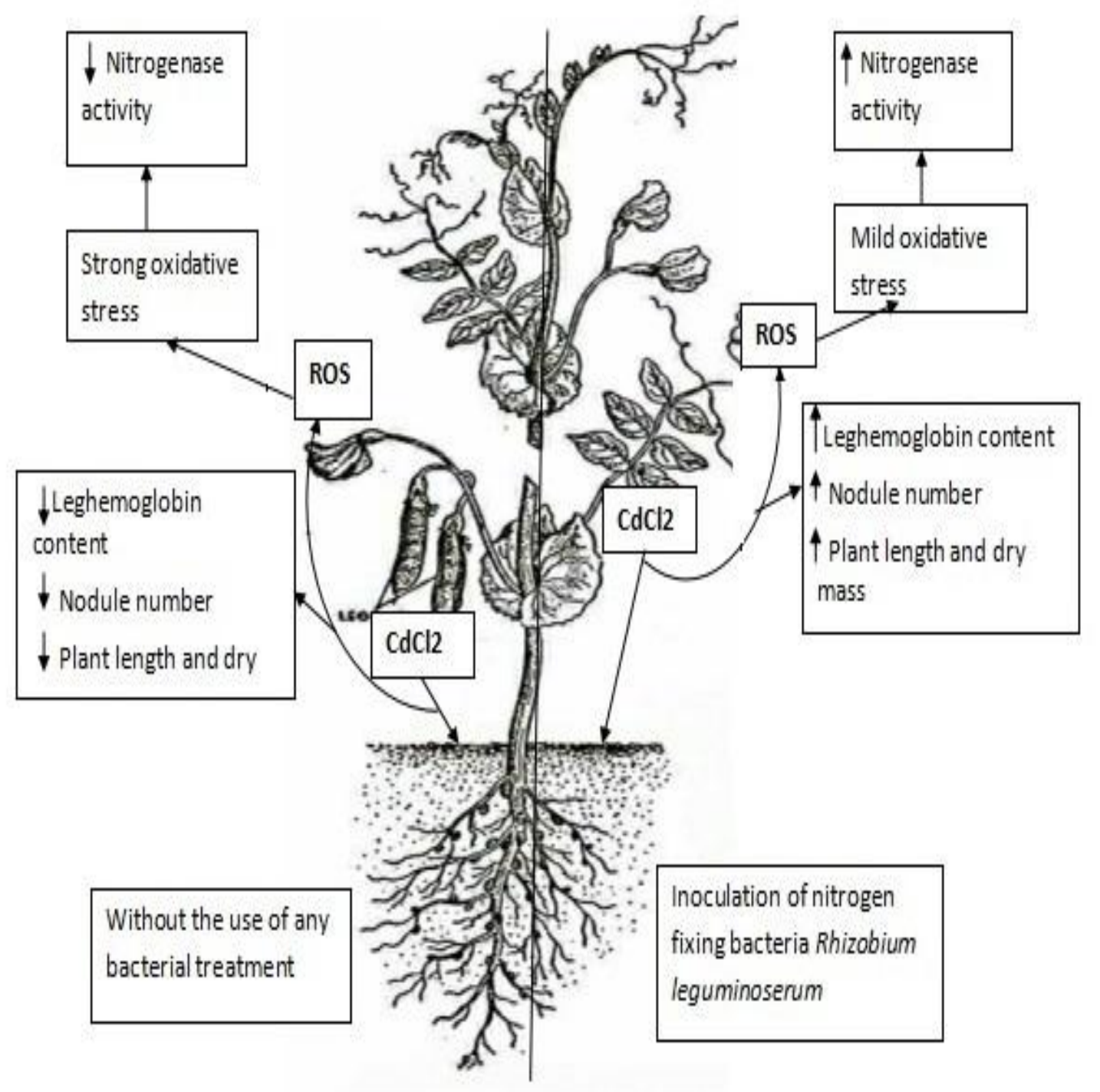


Fig.5 Effects of Zn exposure alone and in combination with nodule Rhizobacteria on selected growth parameters and ROS homeostasis in Lens culinaris plants. Arrows $\uparrow \&$ tindicates the increase and decrease in the parameters respectively.

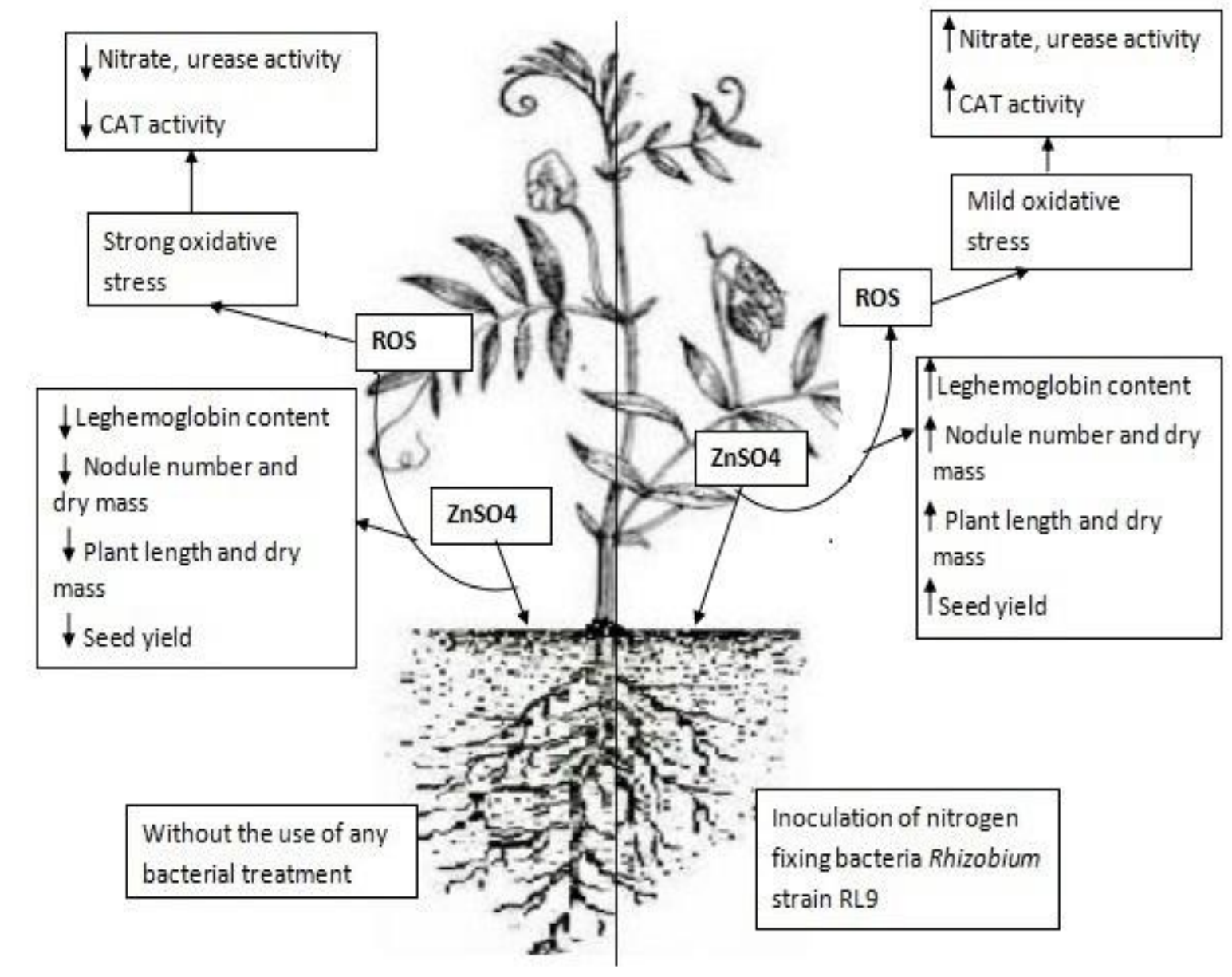

Wani et al., (2008) carried out an experiment with aim to know the nickel and zinctolerance efficiency against plant growthpromoting (PGP) Rhizobium sp., they have isolated RP5 strain from nodules of pea, grown in metal-contaminated Indian soils under in vitro conditions and found that strain RP5 displayed a high level of tolerance to nickel $\left(350 \mu \mathrm{g} \mathrm{ml}^{-1}\right)$ and zinc $\left(1500 \mu \mathrm{g} \mathrm{ml}^{-1}\right)$ and showed PGP activity. It is also noticed that the leghaemoglobin content in fresh nodules accelerated significantly by 30 percent at $4890 \mathrm{mg} \mathrm{Zn} \mathrm{kg}^{-1}$ soil, compared with control. Now days, several studies related to the potential exploitation of rhizobium legume symbioses for phytoremediation have increased enormously as a result of environmental emergencies. A large numbers of investigations have claimed that rhizobia, and especially heavy-metal resistant rhizobia, can increase legume heavymetal tolerance and promote improved legume growth in metal-rich soils, thereby resulting in greater removal of heavy-metals from the soil. Heavy-metal resistant rhizobia have been isolated from the nodules of legumes grown in heavy-metal rich soil as a result of geological (e.g., serpentine outcrops) or anthropic causes (e.g., mine deposits). Genetic and genomic studies of heavy-metal resistant rhizobia have shown that although relatively few genes acting upon tolerance, a 
much larger set of genes may be involved in maximizing fitness in heavy metal rich growth conditions. Some of these genes, such as the systems for $\mathrm{Ni2}+$ efflux in Sinorhizobium meliloti, may also contribute to a linkage between metal homeostasis (Camilla et al., 2018). Plants which act as hyper accumulator like Pteris vittata L. (Arsenic hyperaccumulator), Azolla spp. (Chromium hyperaccumulator)., Brassica juncea L. (Chromium and zinc hyperaccumulator), Vallisneria americana L. (Chromium hyper accumulator), Medicago sativa L. (Chromium hyperaccumulator), Arabidopsis halleri L. (cadmium hyper accumulator), Noccaea caerulescens L. (cadmium hyperaccumulator), Hellianthus annuus L. (Zinc hyper accumulator), Thalaspi caerulescens L. (Zinc hyperaccumulator) etc. can be planted along with the crops for phytoextraction. These plants can accumulate heavy metals from soils and reduce the heavy metal concentration of agricultural soil.

In conclusion, the knowledge of toxicity due to heavy metals in higher plants and soil plant system has spread as well as increased day by day but still there is blank space in our knowledge. Heavy metals have a negative impact on root growth; shoot growth, dry matter, and physiological activities, interfere the function of gene(s) etc. which leads to significantly lowering the yield of crop plants. Finding of researchers suggest that among all heavy metals it is proved that cadmium is most toxic as to crop plants compared to other metals. Hence, there is urgent need to develop heavy metal tolerance genotypes of pulse crops through traditional and molecular plant breeding approaches. Besides this, the hyperaccumulator plants should be planted in those heavy metal rich regions for phytoextraction. Moreover farmers should avoid the field near to industries and should use fresh underground water instead of the water mixed with industrial waste water when planting pulses or other crops. To meet out the demand of growing population, development of high yielding superior is the priority of plant breeder but develop the tolerance genotypes which can perform better under polluted agricultural soil is need of time. Hence, emphasis should be given to enhance the yield of crops through producing the high yielding genotypes as well as saving the actual yield loss of crops occurred by various factors.

\section{References}

Abbas, G., Khan, M.Q., Jamil, M., Tahir, M. and Hussain F. 2009. Nutrient uptake, growth and yield of wheat (Triticum aestivum L.) as affected by zinc application rates. Inter. J. of Agric. Biol. 11: 389-396.

Ali B., Rani I., Hayat S. and Ahmad A. 2007. Effect of 4-Cl-indole-3-acetic acid on the seed germination of Cicer arietinum exposed to cadmium. Acta Bot. Croat. 66: 57-65.

Andrews, M. 1986. The partitioning of nitrate assimilation between root and shoot of higher plants. Plant Cell Environment 9: 511-519.

Arora, A., Muraleedharan, G.B., Gale, M. and Strasburg A. 1998. Structure-activity relationships for antioxidant activities of a series of flavonoids in a liposomal system. Free Radical Biolog and Medicine. 24 (9): 1355-1363.

Athar, R. and Ahmad M. 2002. Heavy metal toxicity in legume microsymbiont system. J. Plant Nutr. 25: 369-386.

Broadley, M.R., White, P.J., Hammond, J.P., Zelko, I. and Lux A. 2007. Zinc in plant. New Phytology. 173: 677-702.

Burzynski, M. 1988. The uptake and accumulation of phosphorus and nitrates and the activity of nitrate reductse in cucumber seedlings treated with $\mathrm{Pb}$ $\mathrm{Cl} 2$ or $\mathrm{Cd} \mathrm{Cl2}$. Acta. Soc. Bot.Polon. 57: 349-359.

Camilla, F., Alice, C., George, C., Cenzo, Klaudia D.A., Lukasz D., Francesco P. and Alessio M. 2018. Harnessing Rhizobia to Improve HeavyMetal Phytoremediation by Legumes, Genes 9(542): 2-16.

Cataldo, C.D., Garland, T.R. and Widung, R.E. 1983. Cadmium uptake, kinatics in intact soybean plants. Plant Physiol. 73: 844-848.

Chubukova, O. V., Postrigan, B. N., Baimiev, A. and Chemeris, A.V. 2015. The effect of Cadmium on the Efficiency of Development of Legume Rhizobium Symbiosis Biology Bulletin. 42 (5) pp. 
458-462.

Comba, M.E., Benavioes, M.P., Gallego, S.M. and Tonaro M.L. 1998. Relationship between nitrogen fixation and oxidative stress induction in nodules of salt-treated soybean plants. Phyton Int. J. Exp. Bot. 60: 115-126.

Cervantes, C., Garcia, J.C., Devars, S., Corona, F.G., Tavera, H.L. Guzman, J.C. and Sanchez, R.M. 2001. Interactions of chromium with microorganisms and plants. FEMS Microbiology Reviews 25: 335-347.

Dakora, F.D. 1995. A functional relationship between legheamoglobin and nitrogenase based on novel measurement of the two proteins in legume root nodules. Ann. Botany. 75: 4-54.

Dary, M., Chamber-Perez, M., Palomares, A., Pajuelo, E. 2010. In situ phytostabilisation of heavy metal polluted soils using Lupinus luteus inoculated with metal resistant plant-growth promoting rhizobacteria. J. Hazard Mater 177:323-330.

Dhingra, H.R. and Priefer, U.R. 2006. Impact of cadmium on structural and functional aspect of pea (Pisum sativum L.) root nodules. J. Plant Biol. 33: 207-207.

Dixit, V., Pandey, V. and Shyam, R. 2002. Chromium ions inactivate electron transport and enhance superoxide generation in vivo in pea (Pisum sativum L.cv. Azad) root mitochondria. Plant, Cell and Environment 25:687-690.

Dowdy, R.H. and Ham G.E. 1977. Soybean growth and elemental content as influenced by soil amendments of sewage sludge and heavy metals: Seedling studies. Agronomy Journal 69(2): 300303.

Fernandez-Pascual, M., de Lorenozo, C., de Felip, M.R., Rajalakshmi, S., Gordon, A. J., Thomas, B.J. and Minchin, F.R. 1996. Possible reasons for relative salt stress tolerance in nodules of white lupin cv. Multolupa. J. Expt. Bot. 47 (304): 17091716.

Freeman, J. L., Persans, M. W., Nieman, K., Albrecht, C., Peer, W., Pickkering, I.J. and Salt, D.E. 2004. Increased glutathione biosynthesis plays a role in nickel tolerance in Thlaspi nickel hyperaccumulators. Plant Cell 16 (8): 2176-2191.

Gill, R.A., Ali, B., Cui, P., Shen, E., Farooq, M.A., Islam, F., Ali, B.M. and Zhou, W. 2016. Comparative transcriptome profiling of two Brassica napus cultivars under chromium toxicity and its alleviation by reduced glutathione. BMC Genomics. 17:885-910.

Hao, S., Taghavi, S., Xie, P., Orbach, M.J., Alwathnani, H.A., Rensing, C., and Wei G. 2014. Phytoremediation of heavy and transition metals aided by legume-rhizobia symbiosis. International Journal of Phytoremediation. 16:179-202.
Hasan, S.A., Ali, B., Hayat S. and Ahmad A. 2007b. Cadmium induced changes in the growth and carbonic anhydrase activity of chickpea. Turkish J. Biol. 31:137-140.

Hasan, S.A., Fariduddin, Q., Ali, B., Hayat, S. and Ahmad, A. 2009. Cadmium: Toxicity and tolerance in plants. J. of Environ. Biol. 30(2):165174.

Hasan, S.A., Hayat S., Ali B. and Ahmad A. 2007a. 28homobrassinolide protects chickpea (Cicer arietinum L.) from cadmium toxicity by stimulating antioxidant. Environ. Pollut. 151:6066.

Hernandez, L.E., Garate, A. and Carpena-Ruiz-Ruiz. 1995. The effect of cadmium on symbiotic nitrogen fixation of pea (Pisum sativum) plant grown in perlite and vermiculite. J. Plant Nutr. 18: 287-303.

Hossain, M.A., Piatida, P., Silva J.A.T. and Fujita, M. 2012. Molecular mechanismof heavy metal toxicityand tolerance in plants: Central role of glutathione in detoxification of reactive oxygen species and methylglyoxal and in heavy metal chelation. Journal of Botany. 2012: 1- 37.

Ibrahim, S. and Shabbir, S. 2014. Effect of Zinc on Lentil (Lens culinaris L.) Metabolites and Antioxidant Enzyme Activities. 5 (1): 20-24.

Jung, C.H., Maeder, V., Funk, F., Frey, B., Stich Er, H., Fros Erd E. 2003. Release of phenols from Lupinus albus $\mathrm{L}$. roots exposed to $\mathrm{Cu}$ and their possible role in $\mathrm{Cu}$ detoxification. Plant Soil 252: 301-312.

Katz, S.A. and Salem H. 1994. The Biological and Environmental Chemistry of Chromium, VCH, Weinheim, pp. 14.

Lytle, C. M., Lytle, F. W., Yang, N., Qian, J.H., Hansen, D., Zayed, A. and Terry, N. 1998. Reduction of $\mathrm{Cr}$ (VI) to $\mathrm{Cr}$ (III) by wetland plants: potential for in situ heavy metal detoxification. Environmental Science and Technology. 32 (20):3087-3093.

Mc Granth, S.P., Brookers, P.C. and Giller K.E. 1988. Effects of potentially toxic metals in soil derived from past applications of sewage sludge on nitrogen fixation by Trifolium repens. Soil Boil. Biochem. 20: 415-425.

Mittler R., Vanderauwera S., Gollery, M. and Van Breusegem, F. 2004. Reactive oxygen gene network of plants. Trends Plant Sci. 9: 490 - 498.

Morgan, J.F., Klucas, R.V., Gray Er, R.J., Abian, J., Becana, M. 1997. Complexes of iron with phenolic compounds from soybean nodules and other legume tissues: peroxidant and antioxidant properties. Free Radic. Biol. Med. 22:861.

Naz, H., Naz, A. and Ashraf S. 2015. Impact of Heavy Metal Toxicity to Plant Growth and Nodulation in 
Chickpea Grown Under Heavy Metal Stress. International Journal for Research in Emerging Science and Technology 2 (5): 248-260.

Neumann, H., Bode-Kirchhoff, A., Madeheim, A. and Wetzel, A. (1998) Toxicity testing of heavy metals with the Rhizobium-legume symbiosis: High Sensitivity to cadmium and arsenic compounds. Environ Sci. Pollut. Res. Int. 5(1): 28-36.

Pajuelo, E., Rodríguez-Llorente, I.D., Lafuente, A. and Caviedes, A. 2011. Legume-Rhizobium Symbioses as a Tool for Bioremediation of Heavy Metal Polluted Soils. Biomanagement of MetalContaminated Soils. 20:95-123.

Parr, P.D. and Taylor, Jr. F.G. (1982) Germination and growth affects of Hexavalent chromium in Orocol TL (a corrosion inhibitor) on Phaseolus vulgaris. Environment International 7:197-202.

Phalcon, A.M. 1989. Toxicity of heavy metals ( $\mathrm{Zn}, \mathrm{Cu}$, $\mathrm{Cd}, \mathrm{Pb})$ to vascular plants. Water Air Soil Pollut. 47:287-319.

Pooniya, V., Choudhary, A.K., Dass, A., Bana, R.S., Rana, K.S., Rana, D.A., Tyagi, V.K. and Puniya, M.M. 2015. Improved crop management practices for sustainable pulse production: An Indian perspective. Indian Journal of Agricultural Sciences 85 (6): 747-58.

Prasad, M.N.V. and Freitas, H.M. 2003. Metal hyperaccumulation in plants - Biodiversity prospecting for phytoremediation technology. Electronic Journal of Biotechnology. 6(3):285321.

Quddus, M. A., Naser, H.M., Hossain, M. A. and Hossain, M.A. 2014. Effect of Zinc and Boron on yield and yield contributing characters of lentil in low Ganges River Floodplain soil at madaripur, Bangladesh. Bangladesh J. Agril. Res. 39(4): 591603.

Rout, G.R. , Samantaray, S., Das, P. 2000. Effects of chromium and nickel on germination and growth in tolerant and non-tolerant population of Echinochloa colona (L). link. Chemosphere 40(8): 855-859.

Sakihama, Y., Masaki, H. 2002. Lipid peroxidation induces by phenolics in conjunction with aluminium ions. Biol. Plantarum 45:249.
Shalini, C. and Vijai P. 2018. Biochemical responses of lentil (Lens culinaris Medik) to zinc and iron nutrition in zinc deficient soil. Journal of Pharmacognosy and Phytochemistry 7(4): 23442348.

Shankar, A.K. and Pathmanabhan, G. 2004. Speciation dependent antioxidative response in roots and leaves of Sorghum bicolor L. Moench cv CO 27under Cr. (VI) stress. Plant Soil. 265:141-151.

Shankar, A.K., Djanaguiraman, M. and Venkateswarlu, B. 2009. Chromium interactions in plants: current status and future strategies. The Royal Society of Chemistry 1: 375-383.

Shen, X.Y., Dai, J.Y., Hu, A.C., Gu, W.L., He, R.Y. and Zheng B. 1990. Studies on physiological effects of brassinolide on drought resistant in Maize. Journal of Shenyang Agricultural University. 21(3):191-195.

Singh K. K., Praharaj C. S., Choudhary A. K., Kumar, N.and Venkatesh M. S. (2011). Indian Journal of Fertlilizers 7 (10): 118-126.

Siripornadulsil, S., Traina, S., Verma, D.P.S. and Sayre, R.T. 2002. Molecular mechanisms of proline-mediated tolerance to toxic heavy metals in transgenic microalgae. Plant Cell. 14 (11):28372847.

Van A. F. and Clijsters, H. 1990. Effects of metals on enzyme activity in plant. Plant Cell Environ. 13:195-206.

Vigue, G.T., Pepper I.L. and Bezdicek D. F. 1981. The effect of cadmium on nodulation and nitrogenacetylene fixation by dry mass (Phaseolus vulgaris L.). J. of Environ. Qual. 10, 87-90.

Wani, P.A., Khan, S, and Zaidi, A. 2008. Effect of Metal-Tolerant Plant Growth-Promoting Rhizobium on the Performance of Pea Grown in Metal-Amended Soil. Archives of Environmental Contamination and Toxicology. 55:33-42.

Weckx, J.E.J., and Ciljsters, H.M. 1997. Zn phytotoxicity induces oxidative stress in primary leaves of Phaseolus vulgaris L. Plant Physiol. \& Biochem. 35:405-410.

Wink El.-Shriley, B. 2002. Biosynthesis of flavonoids and effects of stress. Current Opinion in Plant Biology, 5: 218-223.

\section{How to cite this article:}

Srabani Kar and Ravindra Prasad. 2020. Adverse Effects of Chromium, Cadmium and Zinc on the Growth and Metabolic Activities of Pulse Crops and their Key Management Strategies: A Review. Int.J.Curr.Microbiol.App.Sci. 9(04): 48-63. doi: https://doi.org/10.20546/ijcmas.2020.904.008 